ISSN: 2345-2897; Health Education and Health Promotion. 2019; 7(3):111-117
Effectiveness of School-Based Mindfulness Training as a
Program to Prevent Stress, Anxiety, and Depression in High

\section{A R T I C L E I N F O}

\section{Article Type}

Original Research

\section{Authors}

Mostafazadeh P. ${ }^{1} M S c$,

Ebadi Z. ${ }^{2} P h D$,

Mousavi S. ${ }^{* 2} M S c$,

Nouroozi N. ${ }^{3} M S C$

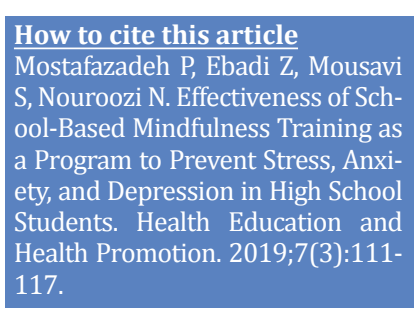

${ }^{1}$ Clinical Psychology Department, Psychology Faculty, Tehran Medical Branch, Islamic Azad University, Tehran, Iran

${ }^{2}$ Psychology Department, Psychology Faculty, Payame Noor University, Tehran, Iran

${ }^{3}$ General Psychology Department, Literature Faculty, Izeh Branch, Islamic Azad University, Izeh, Iran

\section{*Correspondence}

Address: Psychology Faculty, Payame Noor University, Noorabad Coy, Tarisha Alley, Ahvaz, Iran. Postal Code: 6391696932

Phone: +98 (61) 43651252

Fax: +98 (61) 43651252

saramhasti@yahoo.com

\section{Article History}

Received: December 05, 2018

Accepted: May 18, 2019

ePublished: July 21, 2019

\section{A B S T R A C T}

Aims The aim of this study was to investigate the effectiveness of the implementation of mindfulness training on depression, anxiety, and stress in high school students in Ahvaz in the academic year of 2017-2018.

Materials and Methods This is a quasi-experimental study with pre-test post-test design with control group. The statistical population included all of high school female students in the academic year of 2017-2018. The sample size consisted of 40 students, who were selected by multi-stage cluster sampling and randomly divided into experimental $(n=20)$ and control $(n=20)$ groups. For the experimental group, 8 sessions (each session 90 minutes) of the mindfulness program were performed, but no experimental test was performed for the control group and the Depression Anxiety Stress Scales (DASS) was used for collecting data. To test the hypotheses, covariance analysis and multivariate analysis of variance was performed, using SPSS 21 software. In addition, Levin test was used to test the equivalency of variances. After completion of educational programs, post-test was performed on both groups.

Findings The results of data analysis indicated that the effect of mindfulness training on decreasing depression, anxiety, and stress has been shown and there was a significant relationship between mindfulness education and anxiety reduction, depression, and stress $(\mathrm{p}<0.01)$.

Conclusion Based on the results of this study, it is worthwhile for educators to teach students how to train their mind-learning skills to be able to manage their self-control coping processes and reduce the amount of anxiety disorder in psychological conditions.

Keywords Mindfulness; Training; Anxiety; Stress; Depression

\title{
CITATION LINKS
}

[1] An outpatient program in behavioral ... [2] Full Catastrophe Living: Usingthe Wisdom ... [3] A model of mindful parenting: implications ... [4] Effects of mindfulness on psychological ... [5] The effects of mindfulness meditation ... [6] Prevalence and incidence studies of anxiety ... [7] The effect of cognitive training on the ... [8] Evaluation of the correlations between depression ... [9] Effects of Mindfulness-Based Stress Reduction ... [10] Effectiveness of mindfulness-based stress reduction ... [11] Comparison of perfectionism, aggression and coping ... [12] Efficacy of family anxiety management training ... [13] The effectiveness of mindfulness-based stress reduction ... [14] Efficacy of mindfulness-based cognitive therapy ... [15] Effectiveness of teaching mindfulness techniques on ... [16] Mindfulness-based stress reduction for healthy ... [17] Effects of mindfulness-based stress reduction on ... [18] The effect of mindfulness-based techniques in reduction ... [19] Effectiveness of cognitive learning strategies on test anxiety ... [20] Students and teachers benefit from mindfulnessbased stress ... [21] Comparative effectiveness of group mindfulness-based cognitive ... [22] Mindfulness-based stress reduction: a literature review and ... [23] The role of mindfulness in reducing the adverse ... [24] The effect of mindfulness-based therapy on anxiety ... [25] Minding one's emotions: mindfulness training ... [26] School-based mindfulness intervention for ... [27] Mindfulness-based cognitive therapy for depression ... [28] Self-determination theory and the facilitation ... [29] Dimensions of well-being: research and ... [30] Improving self-regulation in adolescents: current ... [31] How mindfulness training promotes positive ... [32] Acceptance lowers stress reactivity: Dismantling ... [33] Mindfulness based stress reduction for school ... [34] Cross-sectional study of anxiety symptoms in students in ... [35] The comparison of the effectiveness of mindfulness and ... [36] Manual for the depression anxiety stress ... [37] Psychometric properties of the Depression Anxiety ... [38] Mindfulnessbased stress reduction for ... [39] The role of mindfulness facets in affective ... 


\section{Introduction}

The most common method for teaching mindfulness is the education of mindfulness-based stress reduction (MBSR), which is known as depression, anxiety, and stress reduction program and educational relaxation program [1, 2]. This method can be effective by increasing coping skills among vulnerable students [3]. In general, evidences from researches showed that mindfulness is positively associated with different mental health indicators, such as higher levels of self-esteem, life satisfaction, resilience, and emotional regulation, low levels of negative effects, and psychiatric symptoms. There is growing evidence of neurobiological and laboratory behavioral research that emphasizes the concentration of mindfulness in reducing responses to emotional stimuli and increasing psychological health [4]. Although the purpose of mindfulness is promoting consciousness without judging and accepting the individual's experiences without changing them, it decreases the symptoms of stress and anxiety due to participation in mind-awareness education programs [5]. Learning effective management practices and reducing stress are a special skill for many psychiatric clients since stress often leads to increased anxiety [6].

The researches revealed that between $8 \%$ and $12 \%$ of children and up to $10 \%$ of adolescents have one of the diagnostic criteria of anxiety disorder that disturbed the normal course of life and daily functioning [7-10]. However, girls are more likely to develop anxiety disorders than boys are [11]. These problems often start from the age of preschool and they show a higher level of behavior in primary school [12]. Researches have shown that many children and adolescents exposed to adverse experiences in childhood that may lead to stress and depression, which is associated with an increase in adult mortality [13-17]. Studies in children and adolescents also showed that mental health interventions improve behavioral and physical outcomes [18-22]. According to this research, highquality education and mental concentration can reduce the negative effects of stress and childhood stress exposure [23].

Many studies have shown that the education of mindfulness reduces stress. In 2010, Hoffman et al. concluded in a meta-analysis of 39 that mindfocused therapy might be useful in changing the emotional and cognitive processes that are different in clinical practice [24]. These findings are evidenced by the fact that meditation of mindfulness increases the positive effect and decrease the negative impact of anxiety. Findings show that meditation of mindfulness regulates the ability of individuals to use coping strategies [25, 26]. Cross sectional studies show a decrease in symptoms of depression with positive changes in mindfulness skills, quality of life, and rumination [27]. The presence of the mind can help individuals to get rid of their thoughts, to help unhealthy habits and patterns of behavior, and, thus, play an important role in regulating behavior [28]. Therefore, the change in awareness and the creation of a new relationship with thoughts, as compared to their change, is emphasized. Mentality provides a variety of ways to deal with excitement, pain, and distress. It assumed that the lack of a relationship with negative thinking creates a skill that is not involved in mental ruminations [29].

The importance of research on the dimensions of mindfulness among students is that the meditation of mindfulness training triggers the activation of a region of the brain that produces positive emotions and beneficial effects in the function of immunization of the body [30]. Teaching and practicing mindfulness in preventing and educating young people is a popular strategy for creating selfregulatory skills among children and adolescents as a promising strategy. The mind of consciousness is the focus of what is happening right now and informed of every moment without conceptual judgment [30]. New research on contemporary education has identified a range of benefits of mindfulness training with children and adolescents, including increased attention, behavior, emotion regulation, effective stress responses, and socialemotional competence, as well as the reduction of depression, anxiety, and external behaviors [31, 32]. Findings of the research have shown that mindfulness education facilitates the selfassessment ability in adolescents [33].

Similarly, the increased levels of stress may lead to spread of anxiety-related psychiatric disorders, which can disrupt overall performance [34]. Therefore, recognizing the effects of this type of intervention, in particular, training on the reduction of depression, anxiety, and stress based on the mindfulness in interpersonal relationships is essential. One of the important goals and tasks of education is to create the fields of development for the students and to educate healthy, efficient, and responsible people for playing a role in personal and social life. Since students as a pillar of the education system of the country play a special role in achieving the goals of the educational system, paying attention to this group of society in terms of education and training causes to increase fertility and prosperity of the educational system of society.

Depression, anxiety, and stress are the factors that threaten the health of students. Depression, anxiety, and stress, if being high, cause feelings of anger, fear, and failure, and endanger the physical, mental, and student's mind [35].

One of the many benefits of mindfulness practices is the ability to better understand the relationship between thinking, emotional experience, and physical action, helping us to respond appropriately to stimuli instead of reacting impulsively (Figure 1). 
According to the sentences mentioned before, the present study used to assess the factors affecting the reduction of depression, anxiety, and stress due to the inevitability of some stress, anxiety, and depression in girl adolescents and the need for prevention. The psychological and behavioral are helpful to reduce the depression, anxiety, and stress of this group of students. Therefore, the research question suggests whether the implementation of mindfulness education is effective in decreasing the depression, anxiety, and stress of high school girl students in Ahvaz.

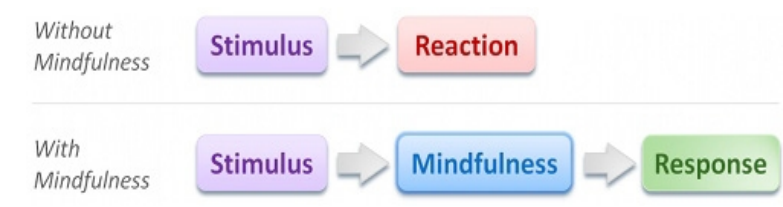

Figure 1) The model of without and with mindfulness

\section{Materials and Methods}

This study is an experimental/quasi-experimental research in the form of a group design with pre-test and post-test with a control group with an interventional method. Based on our society, all students of high school in Ahvaz were from 2017-18. In this research, the cluster sampling method of 3 schools was selected through the high school girls in Ahvaz. Among them, 40 students were selected according to the criteria of research (inclusion and exclusion criteria) in order to determine the effectiveness of mindfulness. Allocations in the experimental and control groups $(20$ in the experimental group and 20 in the control group) were randomized. Table 1 shows the scoring of the Depression Anxiety Stress Scales (DASS).

Table 1) The scoring of the DASS

\begin{tabular}{lccc}
\multicolumn{1}{c}{ Range } & Depression & Anxiety & Stress \\
\hline Normal & $0-9$ & $0-7$ & $0-14$ \\
Mild & $10-13$ & $8-9$ & $15-18$ \\
Moderate & $14-20$ & $10-14$ & $19-25$ \\
Severe & $21-27$ & $15-19$ & $26-33$ \\
Extremely Severe & $28+$ & $20+$ & $34+$ \\
\hline
\end{tabular}

Mindfulness-Based Stress Reduction for Teens (MBSR-T): The 'Stressed Teens' Programme

The inclusion criteria of the research consisted of the age range of 15-18 years, those who were identified as stress-stricken, anxious, and depressed students, and exclusion criteria included the absences of more than 2 sessions and nonperforming assignments from the beginning of the sessions of the mind (Table 2). It should be mentioned that after explanation of the research objectives, informed consent was obtained from each participant.

Research Tool: DASS was used for collecting data. The scale of depression, anxiety, and stress are constructed to measure the psychological structures of depression, anxiety, and stress. The original version of this scale has 42 questions that measure depression, anxiety, and stress [36]. Later, Lovibond and Lovibond [36] created a shorter version of the scale, called DASS-21. Confirmatory factor analysis confirmed the existence of 3 levels of depression, anxiety, and stress with 7 phrases. In a study conducted by Asghari et al. [37], the correlation coefficient of depression, anxiety, and stress scales was $0.93,0.90$, and 0.92 and reminder factors (3 weeks interval), depression, anxiety, and stress scales were 0.84 and 0.90 , respectively. In addition, the within-group correlation between the two exercises was $0.78,0.87$, and 0.80 , respectively.

DASS Severity Ratings: The DASS is a quantitative measure of distress during 3 axes of depression, anxiety, and stress. This measure is not absolute for clinical diagnosis. Emotional syndromes, such as depression and anxiety are inherent in nature that vary throughout a continuum of severity (independent of the specific diagnosis). Hence, the choice of a cut-off score is strictly necessary to demonstrate clinical severity. The DASS scale can lead to a beneficial evaluation of the disorder; for example, those who may prevent clinical discontinuation for a specific diagnosis can be properly identified as significant symptoms and are known to be a greater risk of problems.

However, for clinical purposes, it may be useful to have labels to indicate the severity of the population. Therefore, the following cut-off scores have been developed to determine normal/mild/moderate/severe/extremely severe scores for each DASS scale. The severity tags are used to describe a wide range of scores in the population. Thus, "mild" means that the person is higher than the population, but it is still likely to be less than the intensity of the person, who seeks help (This does not mean that the individual DASS scores do not define appropriate interventions). They should be used in conjunction with all clinical information available to you in determining the appropriate treatment for any individual [36].

Mindfulness-Based Stress Reduction for Teens (MBSR-T): The 'Stressed Teens' Programme like MBSR-C, Stressed Teens (MBSR-T) is based on the empirically validated MBSR programme for adults, and has been adapted for adolescents aged 13-18 years. MBSR-T is taught over the course of 8 weeks and comprises one 1.5-hour session per week, as well as home practice. The programme utilises various strategies for cultivating greater body awareness, self-care, mindful resilience, working with thoughts and unpleasant events, developing an awareness of positive experiences, coping, letting go, and forgiveness. It also includes components that explore a mindful approach to homework and testtaking [38].

Data analysis: In order to compare the mean posttest mindfulness training scores in both groups, covariance analysis (ANCOVA) was used after 
controlling the effect of the pre-test. The data were analyze by SPSS 21 software, using descriptive statistics including mean, standard deviation, and inferential statistics including covariance and variance. Finally, both groups were subjected to post-test.

Table 2) An educational study program based on mindfulness training content sessions

\begin{tabular}{|c|}
\hline MBSR-T Session \\
\hline Description \\
\hline $\begin{array}{l}\text { We begin learning the specifics of the 8-session MBSR-T approach. In this session, you will learn how to help your teen } \\
\text { clients learn about stress, their intentions, and goal setting. Discover specific methods to introduce mindfulness to your } \\
\text { clients, as well as how to guide them in developing a personal mindfulness practice to overcome barriers to success. } \\
\text { Key teen-specific interventions }\end{array}$ \\
\hline Life Stressors: What is Stressing You Out; Mindfulness and the Five Senses; Mindful Eating-Taking a Mindful Bite \\
\hline MBSR-T Session 2 \\
\hline Description \\
\hline $\begin{array}{l}\text { This week you will learn how to conduct session } 2 \text { of the Stressed Teens program, which teaches clients about the } \\
\text { physical and emotional effects of stress they may be experiencing. We will focus on developing the correct setting and } \\
\text { timing for mindfulness practices both in and out of sessions, as well as how to maintain flexibility in your program. } \\
\text { Key teen-specific interventions }\end{array}$ \\
\hline $\begin{array}{l}\text { Paying Attention to Red Flags-Fight, Flight, or Freeze Response; Body-Mind Connection; Stress Helpful/Harmful Curve; } \\
\text { Body Scan Mindfulness Practice and Debrief }\end{array}$ \\
\hline
\end{tabular}

Body Scan Mindfulness Practice and Debrief

\section{Description}

MBSR-T Session 3

In session 3 of the MBSR-T program, you will learn how to guide your teen clients in further developing and

strengthening their personal mindfulness practice by bringing mindfulness and awareness to routine tasks and interests in their everyday lives.

Key teen-specific interventions

Accepting Your Emotions: The Guest House Poem; Living the Now-Present Moment Awareness; Stress Waves: Riding the Waves of Live; Grounding Anchors: Drop your Anchor; Railroad Activity: Train of Thoughts

*Bonus Practice Session: Conducting the Body Scan*.

\section{Description}

\section{MBSR-T Session 4}

This session focuses on how to cultivate an attitude of self-care and positivity with your teen clients by facilitating an awareness of positive experiences and pleasant moments that occur day-to-day.

Key teen-specific interventions

Mindful Walking and Movement Practice; Pleasant Moments Calendar; Heartfulness Mindfulness Practice; Taking in the Good: Doing What You Enjoy

\section{Description}

\section{MBSR-T Session 5}

This week you will learn to conduct session 5 of the Stressed Teens program to teach your clients to notice and work through their thoughts and experiences - positive AND negative - and respond instead of react.

Key teen-specific interventions

Notice, Being and Working on Thoughts and Judgments; Unpleasant Moments Calendar; Mindful Stopping: Responding Instead of Reacting; Playing Out the End of the Movie

\section{Description}

\section{MBSR-T Session 6}

In session 6 of the program, you will learn how to teach your teen clients to utilize positive coping strategies and

behaviors to manage life's stressors and difficult situations at home, school, and online.

Key teen-specific interventions

Homework and Test-Taking Mindfulness Practice; Self-Awareness Calendar; Self-Harm Awareness Journal; Sitting

Mindfulness Practice

*Bonus Practice Session: Sitting Mindfulness Practice*

\section{Description}

\section{MBSR-T Session7}

In week 9, you will learn how to conduct session 7 of the MBSR-T program, which focuses on helping teens cultivate mindful resilience and build healthy relationships through the practice of mindfulness.

Key teen-specific interventions

Daily Gratitude Practice; Things You Cannot Change and Letting Go Practice; Courage to Change Practice; Trust Exercise:

Mindfulness in Relationships; Mindful Messaging and Posting

\section{MBSR-T Session 8}

\section{Description}

In the final week, you will review the MBSR-T program and assess the mindfulness-based solutions that have been presented with your clients. Uncover strategies to help your clients make mindfulness a continued part of their daily living.

Key teen-specific interventions

Current Status Assessment - Goals and Intentionality; Problems and Mindful Solutions Chart; Mindful Practice Reminders; Letter to Self; Processing Possible Grief and Loss 


\section{Findings}

There was a significant difference between the mean scores of the pre- and post-test of the control group (Table 3). The mean and standard deviation of depression, anxiety, and stress of the experimental group were $76.45 \pm 2.76,8.95 \pm 3.10$, and $12.45 \pm 3.42$, respectively, in the pre-test and $2.95 \pm 2.11,6.90 \pm 3.42$, and 7.20 \pm 3.91 , respectively, in the post-test.

Before the analysis of the hypotheses and applying the covariance analysis test, for ensuring the homogeneity of research variables, the Levin test was used, the results of which are reported below.

The Levin test results is not significant $(\mathrm{p}=0.05$; $\mathrm{F}=0.63$ ). The results show that there are no differences in variance and that they are homogeneous (Table 4).

The results of covariance analysis show that the effect of an independent mindfulness training variable is significant $(p=0.05)$. These results show that the training of mindfulness was effective in reducing depression $(\mathrm{F}=75.11)$ and anxiety $(\mathrm{F}=96.10)$, while mindfulness training was not effective in stress reduction ( $\mathrm{F}=0.22$; Table 5$)$.

Table 3) Mean and standard deviation of variables in pretest and post-test

\begin{tabular}{lcccc}
\multicolumn{1}{c}{ Variables } & $\begin{array}{c}\text { Pre-test } \\
\text { Mean }\end{array}$ & $\begin{array}{c}\text { Pre-test } \\
\text { SD }\end{array}$ & $\begin{array}{c}\text { Post-test } \\
\text { Mean }\end{array}$ & $\begin{array}{c}\text { Post-test } \\
\text { SD }\end{array}$ \\
\hline $\begin{array}{l}\text { Depression } \\
\text { Control }\end{array}$ & 6.70 & 2.75 & 5 & 1.77 \\
Experimental & 7.45 & 2.76 & 2.95 & 2.11 \\
$\begin{array}{l}\text { Anxiety } \\
\text { Control }\end{array}$ & 8.70 & 3.58 & 11.15 & 1.86 \\
Experimental & 8.95 & 3.10 & 6.90 & 3.42 \\
Stress & & & & \\
Control & 11 & 1.86 & 7.80 & 4.47 \\
Experimental & 12.45 & 3.42 & 7.20 & 3.91 \\
\hline
\end{tabular}

Table 4) Levin's Homogeneity results

\begin{tabular}{lccccc}
\multicolumn{1}{c}{ Variables } & f & DF1 & DF2 & Levin's F & sig \\
\hline Depression & 0.392 & 1 & 38 & & 0.53 \\
Anxiety & 1.07 & 1 & 38 & 0.63 & 1.07 \\
Stress & 0.53 & 1 & 38 & & 0.53 \\
\hline
\end{tabular}

Table 5) Mindfulness training has a significant effect on the reduction of Variables

\begin{tabular}{lccccc}
\multicolumn{1}{c}{ Variable } & $\begin{array}{c}\text { Sum of } \\
\text { squares }\end{array}$ & DF & $\begin{array}{c}\text { Mean of } \\
\text { squares }\end{array}$ & F & Sig \\
\hline $\begin{array}{l}\text { Depression } \\
\text { Pre-test } \\
\text { score }\end{array}$ & 3.87 & 1 & 3.87 & 1.01 & 0.32 \\
$\begin{array}{l}\text { Group } \\
\text { Error }\end{array}$ & 44.78 & 1 & 44.78 & 11.75 & 0.002 \\
$\begin{array}{l}\text { Anxiety } \\
\text { Pre-test }\end{array}$ & 141.08 & 38 & 3.81 & & \\
score & 24.93 & 1 & 24.93 & 1.56 & 0.001 \\
Group & 175.27 & 1 & 175.27 & 10.96 & 0.002 \\
$\begin{array}{l}\text { Error } \\
\text { Stress }\end{array}$ & 591.41 & 38 & 15.98 & & \\
$\begin{array}{l}\text { Pre-test } \\
\text { score }\end{array}$ & 0.434 & 1 & 0.434 & 0.02 & 0.87 \\
Group & 4.01 & 1 & 4.01 & 0.22 & 0.64 \\
Error & 671.96 & 38 & 18.16 & & \\
\hline
\end{tabular}

\section{Discussion}

The aim of this study was to implement mindfulness training on reduction of stress, anxiety, and depression in female high school students. The results of covariance analysis show that the effect of an independent variable of mindfulness education is significant. It reduces depression and anxiety and has been effective in reducing stress. The results of this study confirm past research and have a positive effect on the implementation of mindfulness education on the reduction of depression and anxiety. As in this study and previous studies, it has been determined that mindfulness education affects depression and it can lead to an improvement in depression symptoms [22]. These findings are also consistent with [13-18] that mindfulness training reduces anxiety, depression, and stress in the experimental group. It seems that this approach training can reduce students' anxiety, stress, and depression [13] and also reduces the symptoms of depression in patients with generalized anxiety and improves the quality of life and reduces depression [14]. In other words, mindfulness training has been effective in the general health of female students and the subscales of anxiety and insomnia, depression, and social functioning. Participation in this training has led to a decrease in the mean of the experimental group in anxiety and psychological disturbances [15], so that this intervention is effective in reducing stress, depression, anxiety, and improving the quality of life of healthy people [16]. It effectively reduced depression, anxiety, and stress among nursing students [14]; it is also effective in preventing recurrence in patients with major depressive disorder [15].

The optimism and positive emotions increase because of the training of mindfulness, depression, negative affection, and psychological symptoms [38]. Mindfulness helps people to realize that negative excitements may occur, but they are not permanent. It also allows the individual to respond to the reflecting and thinking intentionally rather than responding to the events unintentionally [31]. Therefore, in general, teaching mindfulness can increase self-esteem and escape from the past, which also leads to a reduction in depression.

The results of this study confirm past research and have a positive effect on the reduction of anxiety [12, 18-20]. These studies showed that the education of mindfulness is effective in reducing anxiety, depression, inefficient attitude, and their thoughts [12] in decreasing test anxiety [19]; it significantly reduced the mean anxiety of the experimental group compared to the control group [20], improving selfexpression, and reducing the test anxiety [18]. Yousefian and Asghiripour [21] achieved a positive effect on girls' self-esteem improvement in their study. Moreover, in a review study of the effectiveness of reducing stress based on 
mindfulness training, they found that these programs reduce stress and anxiety in different populations [22]. In previous research, mindfulness training not only reduces stress, but also slowly creates internal forces in order to have less impact on the future stressors, happiness, physical, and mental health [39]. In this study, the report of students' performance by teachers and parents after an intervention can be considered as an advantage of this research.

The limitations of this research, which are due to the conditions governing research, are the students who participated in this study with a different age range of 15-18 years, in which the effect of the age was neglected. However, it is recommended that in future research, the effect of age should be considered as an effective factor in mindfulness education. The difficulty was in organizing timely and regular training sessions and the sample was limited to high schools girls in Ahvaz; therefore, due to the low sample size, the generalization of the findings to other groups should be cautious. Considering the low volume of the groups, the use of self-assessment questionnaire, the effectiveness of an interventional program, lack of follow-up measurements to assess the shelf life of interventions, and lack of knowledge about stress levels and anxiety and depression of students, the generalization of the findings should be cautious. It is suggested that mindfulness education be included as an effective skill and intervention to reduce anxiety, depression, and stress. The focus of schools and the teaching of this approach to teachers can also be helpful for students who have these problems.

\section{Conclusion}

Based on the results of this study, it is worthwhile for educators to teach students how to train their mind-learning skills in order to be able to manage their self-control coping processes and reduce the amount of anxiety disorder in psychological conditions.

Acknowledgments: According to the performance of this research, the authors express their sincere thanks to the all students who participated in this study in Ahvaz.

Ethical Permissions: The authors reported no ethical approval code.

Conflict of interest: None declared.

Authors' Contribution: Mostafazadeh P. (First author), Introduction author/ Original researcher (25\%); Ebadi Z. (Second author), Introduction author/ Methodologist/ Original researcher researcher/ Discussion author (25\%); Mousavi S. (Third author), Methodologist/ Statistical analyst/ Discussion author (35\%); Nouroozi N. (Fourth author), Assistant/Methodologist/ Original researcher/ Statistical analyst/ Discussion author (15\%).

Funding: There is no funding support.

\section{References}

1- Kabat-Zinn J. An outpatient program in behavioral medicine for chronic pain patients based on the practice of mindfulness meditation: theoretical considerations and preliminary results. Gen Hosp Psychiatry. 1982;4(1):3347.

2- Kabat-Zin, J. Full Catastrophe Living: Usingthe Wisdom of Your Body and Mind to Face Stress, Pain and Illness. New York: Random House Publishing Group; 1990.

3- Duncan LG, Coatsworth JD, Greenberg MT. A model of mindful parenting: implications for parent-child relationships and prevention research. Clin Child Fam Psychol Rev. 2009;12(3):255-70.

4- Keng SL, Smoski MJ, Robins CJ. Effects of mindfulness on psychological health: A review of empirical studies. Clin Psychol Rev. 2011;31(6):1041-56.

5- Eberth J, Sedlmeier P. The effects of mindfulness meditation: a meta-analysis. Mindfulness. 2012; 3(3): 17489.

6- Somers JM, Goldner EM, Waraich P, Hsu L Prevalence and incidence studies of anxiety disorders: a systematic review of the literature. Can J Psychiatry. 2006;51(2):10013.

7- Nahravanian P, Askari P, Dortaj F, Naderi F, Bakhtiarpoor S. The effect of cognitive training on the executive function and divided attention of anxious children. J Psychol Achiev. 2017;24(2):43-64. [Persian]

8- Darchini-Maragheh E, Salehi M, Payandeh A, Behdani F, Ghasemzadeh Kolagar H. Evaluation of the correlations between depression, anxiety, and stress as DASS-21 subscales and high-risk behaviors in the adolescents in Torghabeh and Shandiz Towns, Iran. Patient Saf Qual Improv. 2017; 5(3):584-90.

9- Chi X, Bo A, Liu T, Zhang P, Chi I. Effects of MindfulnessBased Stress Reduction on Depression in Adolescents and Young Adults: A Systematic Review and Meta-Analysis. Front Psychol. 2018;9:1034.

10- Shahidi S, Akbari H, Zargar F. Effectiveness of mindfulness-based stress reduction on emotion regulation and test anxiety in female high school students. J Educ Health Promot. 2017;6:87.

11- Abolqasemi A, Jafari I, Ahmadi M. Comparison of perfectionism, aggression and coping styles in patients with migraine and tension type headaches and healthy individuals. J Kerman Univ Med Sci. 2014;21(2):162-73. [Persian]

12- Bassaknezhad S, Shapurabadi F, Davoudi A. Efficacy of family anxiety management training with mothers of anxious preschool children. Zahedan J Res Med Sci. 2014;16(5):45-9.

13- Dehestani M. The effectiveness of mindfulness-based stress reduction program on depression, anxiety and depression of female students. Thought Behav Clin Psychol. 2015;10(37):47-56. [Persian]

14- Kaviani H, Javaheri F, Bahiray H. Efficacy of mindfulness-based cognitive therapy in reducing automatic thoughts, dysfunctional attitude, depression and anxiety: a sixty day follow-up. J Adv Cognit Sci. 2005;7(1) :49-59. [Persian]

15- Taghvaei D. Effectiveness of teaching mindfulness techniques on general health in female secondary school 
117

students of Arak. Clin Psychol Counsel Res. 201;7(1):6776. [Persian]

16- Khoury B, Sharma M, Rush SE, Fournier C. Mindfulness-based stress reduction for healthy individuals: a meta-analysis. J Psychosom Res. 2015;78(6):519-28.

17- Song Y, Lindquist R. Effects of mindfulness-based stress reduction on depression, anxiety, stress, and mindfulness in Korean nursing students. Nurse Educ Today. 2015;35(1):86-90.

18- Beirami M, Abdi R. The effect of mindfulness-based techniques in reduction of students test anxiety. J Psychol Educ Sci. 2010;6(2);35-54. [Persian]

19- Rasouli R, Mohamad Alipour Z, Taghi Pour E. Effectiveness of cognitive learning strategies on test anxiety and school performance of students. Int J Educ Psychol Res. 2018;4(1):20-5.

20- Gouda S, Luong MT, Schmidt S, Bauer J. Students and teachers benefit from mindfulness-based stress reduction in a school-embedded pilot study. Front Psychol. 2016;7:590.

21- Yousefian F, Asgharipour N. Comparative effectiveness of group mindfulness-based cognitive therapy and group cognitive-behavioral therapy on self-esteem of girl students. J Fundam Ment Health. 2013;15(59):205-15. [Persian]

22- Praissman S. Mindfulness-based stress reduction: a literature review and clinician's guide. J Am Acad Nurse Pract. 2008;20(4):212-6.

23- Ortiz R, M Sibinga E. The role of mindfulness in reducing the adverse effects of childhood stress and trauma. Children (Basel). 2017;4(3).

24- Hofmann SG, Sawyer AT, Witt AA, Oh D. The effect of mindfulness-based therapy on anxiety and depression: A meta-analytic review. J Consult Clin Psychol. 2010;78(2):169-83.

25- Farb NA, Anderson AK, Mayberg H, Bean J, McKeon D, Segal ZV. Minding one's emotions: mindfulness training alters the neural expression of sadness. Emotion. 2010;10(1):25-33.

26- Johnston JM, RoakeI C, Sheikh F, Mole A, Nigg JT, Oken B. School-based mindfulness intervention for stress reduction in adolescents: Design and methodology of an open-label, parallel group, randomized controlled trial. Contemp ClinTrial Commun. 2016; 4(15):99-104.

27- Ames CS, Richardson J, Payne S, Smith P, Leigh E. Mindfulness-based cognitive therapy for depression in adolescents. Child Adolesc Ment Health. 2013;19(1):74-8.
Mostafazadeh P. et al.

28- Ryan RM, Deci EL. Self-determination theory and the facilitation of intrinsic motivation, social development, and well-being. Am Psychol. 2000;55(1):68-78.

29- Mace C. Dimensions of well-being: research and intervention. Milano: FrancoAngeli; 2006.

30- Perry-Parrish C, Copeland-Linder N, Webb L, Shields AH1, Sibinga EM. Improving self-regulation in adolescents: current evidence for the role of mindfulness-based cognitive therapy. Adolesc Health Med Ther. 2016;7:101108.

31- Lindsay EK, Chin B, Greco CM, Young S, Brown KW, Wright AGC, et al. How mindfulness training promotes positive emotions: Dismantling acceptance skills training in two randomized controlled trials. J Pers Soc Psychol. 2018;115(6):944-973.

32- Lindsay EK, Young S, Smyth JM, Brown KW, Creswell JD. Acceptance lowers stress reactivity: Dismantling mindfulness training in a randomized controlled trial. Psychoneuroendocrinology. 2018;87:63-73.

33- Saltzman A, Goldin P. Mindfulness based stress reduction for school-age children. In: Hayes SC, Greco LA, editors. Acceptance and mindfulness interventions for children adolescents and families. A practitioner's guide (pp. 139-161). Oakland: New Harbinger Publications; 2008.

34- Yadav P, Chauhan VS, Bhat PS, Agarwal N, Yadav C, Bhatia S. Cross-sectional study of anxiety symptoms in students in preexamination period. Ind Psychiatry J. 2017;26(1):56-63.

35- Narimani M, Ariapouran S, Abolghasemi A, Ahadi B. The comparison of the effectiveness of mindfulness and emotion regulation training on mental health in chemical weapon victims. J Clin Psychol. 2011;2(4):93-110. [Persian]

36- Lovibond SM, Lovibond P FM. Manual for the depression anxiety stress scale. 2nd Ed. Sydney: Psychology Foundation of Australia; 1996.

37- Asghari A, Saed F, Parvin Dibajnia P. Psychometric properties of the Depression Anxiety Stress Scales-21 (DASS-21) in a non-clinical Iranian sample. Inter J Psychol. 2008;2(2):82-102 . [Persian]

38- Biegel GM, Brown KW, Shapiro SL, Schubert CM. Mindfulness-based stress reduction for the treatment of adolescent psychiatric outpatients: A randomized clinical trial. J Consult Clin Psychol. 2009;77(5):855-66.

39- Emanuel AS, Updegraff J A, Kalmbach D A, Ciesla J.A. The role of mindfulness facets in affective forecasting. Personal Individ Differ. 2011;49(7): 815-8. 